\title{
Common Problems in Construction of Road and Bridge and the Application of Quality Inspection Technology
}

\author{
Gang Wang \\ The Engineering \& Technical College of Chengdu University of Technology, Leshan, Sichuan, \\ 614000
}

Keywords: Road and Bridge Construction, Quality Inspection Technology, Problems Fixation

\begin{abstract}
With the rapid development of China's transportation industry, the scale of road and bridge works is increasing, and the construction quality of road and bridge has become an important work content of the transportation industry. The quality of the road bridge project is in addition to the material, the quality of construction personnel and construction management, but also by the construction technology interference. This paper analyzes the common technical problems in the construction of road and bridge, and puts forward the corresponding measures to ensure the quality of road and bridge construction.
\end{abstract}

\section{Introduction}

The traffic industry must attach great importance to the bridge construction related issues, technology is the road bridge construction in the center of the important factors, road and bridge construction units should firmly grasp the key link of technology, the use of technical strengthening and technical measures to prevent the comprehensive To ensure the overall quality of road and bridge construction. Based on the actual construction of road and bridge construction, this paper illustrates the causes of construction problems of various types of road bridges, and provides the solutions to the problems of road and bridge construction technology. It is based on the angle of transportation construction and the level of technology Reconstruction of road and bridge construction industry. The construction quality of road and bridge construction can not be separated from the actual accumulation and summary of road and bridge construction. On the basis of scientific description of common problems in road and bridge construction, it is necessary to solve the problem of construction technology problem of all kinds of road and bridge construction and seek the solution of road and bridge construction technology Measures to transport the construction of the perspective and technical aspects of the road bridge construction industry deconstruction, as a whole to enhance the bridge construction technology capacity and level.

The quality of the road bridge determines whether the safety of people driving the process of people's lives have an important impact. But the current road bridge in China in the construction process there are still some quality problems. Namely: 1, roads and bridges connected sections of the settlement phenomenon. Many drivers will find that when the vehicle is ready to bridge or bridge when the vehicle will jump in the bridge phenomenon. The root cause of the phenomenon of vehicle jumping is that the settlement between the abutment and the road is damaged and the settlement value of both the abutment and the road has exceeded the maximum sedimentation value, causing the vehicle to bump in the normal running process and Other emergencies. Which led to the road and the abutment of a large settlement is due to the construction process of the construction unit is not sufficient equipment without the abutment and the road to give the appropriate compaction led to the phenomenon of settlement. At present, many bridges in our country will be cracks this is a common problem for all bridges. The direct cause of the occurrence of cracks is due to the construction of materials used in the construction of our main roads and bridges. On the one hand, the quality of raw materials used as a bridge for concrete construction can not reach the standard required by the bridge construction. Therefore, it can not withstand the long time carrying the final security problem. On the other hand the reasons for the occurrence of cracks also have the reasons for the construction unit construction unit in the construction process without reasonable use of concrete alone with the staff on the subjective work experience to determine the use of 
concrete in the water when the concrete is not properly watering Method to remove the concrete template after the bridge is not timely and effective maintenance of the bridge because of a large number of lack of moisture and fracture.

\section{Analysis on the Cause of Construction Technology of Road and Bridge}

The first concrete vibrations are insufficient. Due to the prestressed pipe in the web is too dense in the concrete pouring is extremely easy to cause the local location of the concrete vibrate the lack of density caused by concrete appear Ma, holes and other quality defects. Second, the impact of temperature stress in the early stages of concrete pouring cement hydration heat will accumulate in the concrete can not be distributed inside the internal temperature will cause the rise, causing the concrete surface expansion stress due to the initial tensile strength of concrete and the surface Of the tensile stress is easy to exceed the ultimate tensile strength of concrete, which will lead to concrete cracks reduce the strength of the road bridge. The third road bridge prestressed pipe in the construction of the lack of accuracy in the line so that the pipeline is not rounded or local bending, causing the location of the prestressed tendons and the actual location of the deviation, it is easy to cause cracks. The fourth road bridge contractor to a relatively low price contract to the project in order to obtain profits from the low quality and low cost of construction materials are applied to the project which shoddy construction machinery and equipment are also frequent failures.

\section{Road Bridge Construction Technology Problem Solving Measures}

There are many types of foundation treatment technology, such as soft soil foundation, embankment foundation or collapsible loess foundation. The different nature of the foundation is different, and corresponding measures are needed according to the actual situation. There are several kinds of grouting method, spin-spinning method, stirring method and replacement method and encryption method.

(1) Grouting method is through the air pressure or hydraulic grouting method to the foundation into the different materials of the slurry, the original ground of water or other discharge or with the original ground reaction, to achieve the purpose of changing the foundation and improve the strength of the foundation. This method is a more widely used method, suitable for all types of foundations, such as soft soil foundation, you can use split grouting method; Chong fill or collapsible loess foundation can use pressure casting method.

(2) Rotary spray method requires the use of rotary spray machine to produce rotary jet piles, rotary spray machine can be placed in the depths of the soil rotation of the special nozzle cement and other solidified liquid into the soil, and layer by layer to enhance So that the soil and cement curing solution combined hardened into a jet grouting pile, suitable for fine sand, red fill or soft clay and other soil foundation.

(3) Mixing method is to add the cement or cement slurry and other curing agent and stirring, so that the foundation and the curing agent between the physical or chemical reaction, the formation of the main and hard mixing, improve the overall strength and water stability of the foundation The This method has the advantages of short construction period and no negative influence on the surrounding buildings.

(4) Replacement method, this method is the use of high strength material to replace the original bed soil layer, so as to improve the stability of the bed and reduce the possibility of deformation. For example, soil replacement, the first base of the original strength of the soil is not up to dig out the soil, and then fill with a greater shear strength, water content and deformation of small materials.

(5) Cryptography through the role of external forces to improve the density of the foundation of the foundation to achieve the purpose of strengthening the strength of the foundation, commonly used in a dynamic compaction method and vibration method. The dynamic compaction method uses a rammer with a weight greater than the specified load to give the foundation a vibration and an impact force, and the vibrating method uses a vibrator to vibrate inside the foundation and adds a 
filler during the process to re Arrange and reduce the gap, thereby reducing its settlement value.

Roadbed treatment technology control subgrade due to long-term impact load such as vehicles, if its density and other deficiencies, prone to compression deformation, therefore, need to minimize the roadbed compression deformation, in the construction need to do the following:

Before filling the roadbed, remove the debris on the surface of the foundation to ensure that the degree of cleanliness of the foundation to avoid the roadbed mixed with debris caused by its structural stability; if the original land for the original, in addition to cleaning the surface, but also on the surface under the $150 \mathrm{~mm}$ The soil is clean; if there are more holes in the foundation, you need to first flattened, and finally with the roller rolling, to ensure the density of the foundation.

Try to improve the strength of the foundation, before filling the roadbed, the first bearing capacity of the foundation to detect the settlement of the roadbed. In general, the bearing capacity of the foundation is as follows: if the height of the rock fill roadway does not exceed $10 \mathrm{~m}$, the bearing capacity of the foundation should be within $150 \mathrm{kPa}$; when the filling height of the rock fill road is greater than $10 \mathrm{~m}$, but not more than $20 \mathrm{~m}$, Force must be more than $200 \mathrm{kPa}$.

To strengthen the roadbed filling construction control, in the roadbed filling construction process, we must first ensure that the selection of filling materials meet the engineering needs, and set up a special technical staff of the roadbed sinking value of the test, and accordingly on the construction Process to adjust, such as filling the thickness of the stone, the working speed of the roller and the number of rolling, etc., do the entire roadbed filling process supervision, thereby enhancing the construction quality of rock fill roadbed.

Reasonable control of the subgrade water content, to minimize its impact on the settlement value and deformation, in the roadbed construction, the need to set the corresponding drainage facilities, so that with the culverts, bridges and other well formed drainage system; Should be provided by the cut-off ditch, side trench and jet tank and other ground drainage measures to the timely roadbed in the surface of the water, slope rain and other surface water discharge.

For the road construction technology prone to the problem, need to control from all aspects of the corresponding. First of all, in order to prevent the occurrence of transverse cracks in the road, the need to use appropriate grade of concrete, and the corresponding insulation design, at the same time, should also improve the concrete pavement compaction, reduce its porosity; in the prevention of longitudinal cracks, To take a scientific mix of concrete to control the thickness of subgrade fill, fill in the roadbed fill as much as possible to achieve uniform and other ways to control. In the prevention of water damage, you can calculate the concrete reinforcement ratio to improve the integrity of the road after completion; to strengthen the control of the road rolling process, before rolling, the first concrete paving flatness, thickness Inspection, to ensure its uniform after rolling, rolling process to comply with the "Ning scraping not fill, rather high not low" principle, to ensure that the road density to meet the relevant standards.

\section{Conclusion}

Due to the many factors that have problems in the construction of road and bridge, there are many different ways of dealing with the need to find out more effective measures through practical efforts and analysis to realize the thorough solution to the problems of road and bridge construction technology. In the context of economic development, the transportation industry should speed up the construction of road bridges in support of economic construction at the same time to make their own rapid development and effective promotion. Road and bridge construction is to strengthen the technology in this central part of the technology to enhance the overall quality of road and bridge construction. Road and bridge construction should be a common technical issues in the industry to start thinking and research, through their own efforts and strive for external support to enhance the dual role of road and bridge construction technology to prevent the problem. To see the road and bridge construction technology to prevent and deal with is a difficult task, to really play all aspects of the advantages and initiative together to be able to do a good job. 


\section{References}

[1] Guo Chang. Talking about the problems and countermeasures in the construction of road bridges [J]. Sichuan Cement, 2016 (04)

[2] Tian Zhenquan. Talking about the Problems and Countermeasures in the Construction of Road and Bridge [J] .Enterprise Science and Technology and Development, 2015 (17)

[3] Shen Hao, Chang Xinyu. Problems and Countermeasures in Construction of Road and Bridge [J]. Science and Technology Information, 2014 (01)

[4] Zhang Jinling. Problems and Countermeasures in the Construction of Road and Bridge in the New Period [J]. Science and Technology Innovation Guide, 2014 (01)

[5] Zhao Feng. Talking about the problems that should be paid attention to in the construction of road and bridge [J] .Science of Science and Technology, 2014 (02)

[6] Jiao Houxiang. Analysis of concrete technology on the impact of bridge construction [J]. China Housing (late), 2013 (11)

[7] Yin Zeyun. The exploration of bridge construction engineering conditions [J]. Technology and Enterprise, 2013 (02) 